\title{
Using Traditional Knowledge Systems for Post-disaster Reconstruction - Issues and Challenges following Gujarat and Kashmir Earthquakes
}

\author{
Rohit Jigyasu
}

\begin{abstract}
In post-disaster situations, traditional constructions are generally considered vulnerable and, therefore, often get replaced by modern ones that are culturally and climatically incompatible, economically unaffordable and, thus, unsustainable in the long run. While it is now known that an enormous wealth of knowledge is embedded within traditional buildings, it is also true that many aspects of this knowledge have become diluted due to the changing social, economic and political context, as well as the needs and aspirations of the people.

Herein lies the dilemma of making the appropriate approach for post disaster reconstruction in developing countries. Should we reject 'outdated' traditional technology and go for a complete break from the past, or should we look backwards and revert to the 'tried and tested' traditional wisdom? A hypothesis has, thus, been raised through this article -- can there be a 'middle way', taking the best of the past and the present, for planning a better future? The article will discuss this core issue in the context of the reconstruction challenges following the 2001 Gujarat earthquake and Northern Kashmir earthquake that struck on 8 October 2005.
\end{abstract}

\section{INTRODUCTION}

Disaster is no longer viewed as an isolated catastrophic event that merely results from momentary natural hazards such as earthquakes, floods, cyclones or tsunamis. The current understanding seeks to recognize the complex relationships between disasters and development. The Hyogo Framework for Action (2005-2015), developed to build resilience to disaster, resolves an effective integration of disaster risk considerations into sustainable development planning and programming at all levels.

To achieve these objectives, the fundamental importance of transmission of traditional technology, skills, and knowledge systems, as well as the conservation of cultural heritage has been recognized, thereby emphasizing the proactive role of cultural heritage management during prevention, response and recovery phases of disaster management (WCDR 2005).

This paper will investigate the scope and nature of traditional knowledge in disaster mitigation, its present status and potential role in post disaster reconstruction by looking into the cases of Kashmir and Gujarat, which suffered devastating earthquakes in 2005 and 2001 respectively.

Creative Space
Vol. 1, No. 1
July 2013
pp. $1-17$

CHITKARA 司 UNIVERSITY University. All Rights Reserved. 
According to official figures, the Northern Kashmir Earthquake, that occured on 8 October 2005, killed more than 87,000 people in Pakistan and 1,300 people in India and, injured 1,00,000 people in Pakistan and 6,600 in India. The devastating earthquake that struck the Kutch region of Gujarat in India on 26 January 2001 killed 20,083 people and injured 166,836.

In both the cases, most structures whether 'modern' or 'traditional', suffered enormous damage causing a massive loss of life and property. Many 'modern' reinforced cement concrete (RCC) constructions, which were largely perceived to be stronger in comparison to traditional structures, were of extremely poor quality. In Kashmir, it was found that many of these buildings did not even follow the basic structural principles of construction in RCC. In many cases, the roof slab was not even resting on the beams. Rather it was cast on two or three courses of brick placed over the beams and, in some constructions, these beams were not even at the same level (Figure 1).

In other cases, the roof slab had been cast virtually without reinforcement bars, while layers of mud for terracing on its top had further increased the dead load. As a result, the roofs simply cracked and collapsed like a pack of cards due to the impact of earthquake (Figure 2). In many structures, even the columns had inadequate reinforcement. There were also instances where structures, with RCC beams resting on slender brick piers, simply gave way due to lateral impact of earthquake.

Most of the traditional structures built with poor quality stone masonry also did not perform well. Although many stone walls were clad with well laid out stone courses, their inner core was built of weak random rubble masonry laid in poor mud mortar. Due to improper bonding and absence of through stones, these walls simply collapsed due to earthquake. (Figure 3) Inadequate corner joints between the perpendicular walls were also one of the reasons for poor behavior of these buildings. In the case of historic structures with sloping roofs, sometimes the free-standing gable walls could not withstand lateral forces of earthquake and simply collapsed.

One of the major reasons for the extensive damage sustained by buildings was incompatible structural and material additions, as a result of which they lost their structural integrity. For example, in several structures originally built of load bearing stone walls, new upper floors were added using RCC.

Needless to stay, lack of adequate knowledge and poor workmanship was the main reason for such an extensive damage of 'modern' RCC as well as traditional stone constructions. Strikingly similar issues were also observed in Gujarat, pointing towards a poor building culture in both the regions prior 

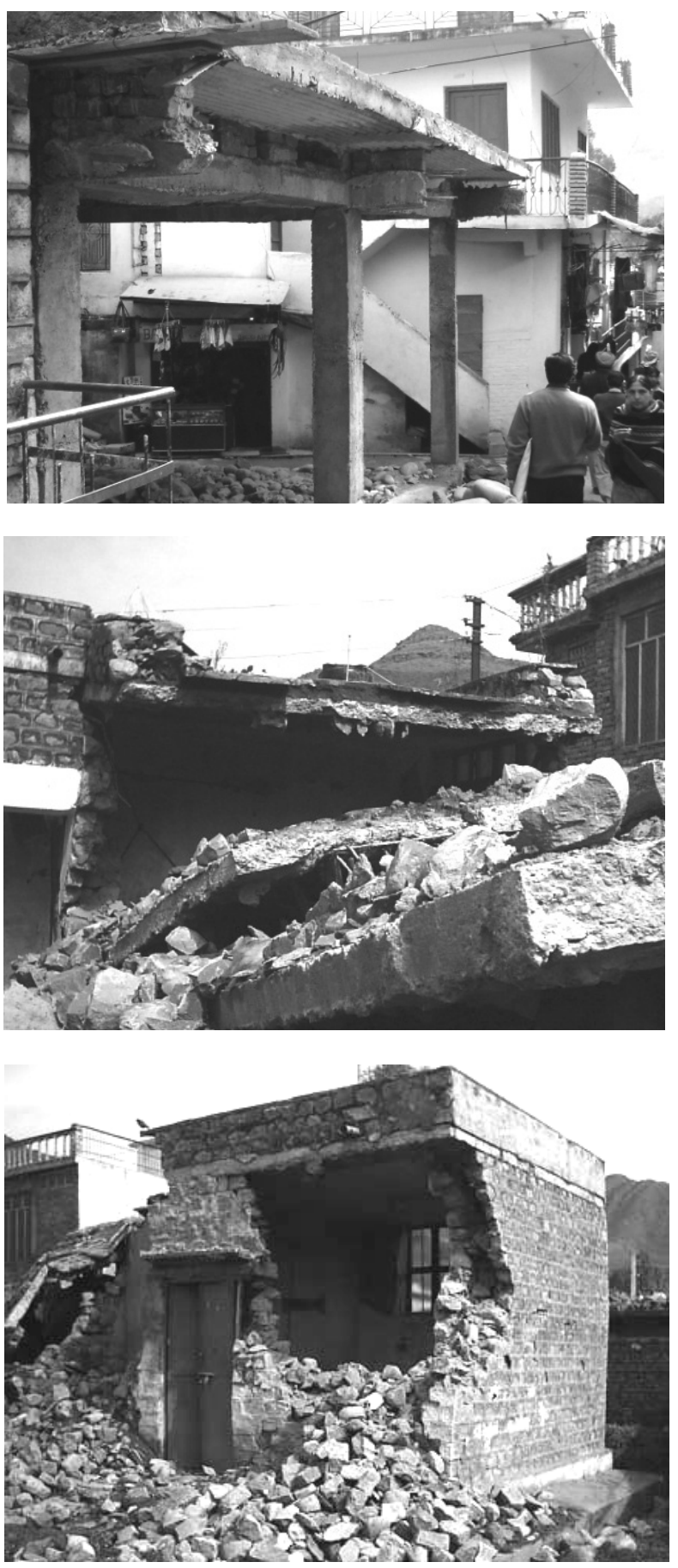

Figure 1:

Poor contemporary

construction in Indianadministered Kashmir with an RCC slab cast on two or three courses of brick placed over beams, which are not even at the same level.
Using Traditional Knowledge Systems for Post-disaster Reconstruction

\section{Figure 2:}

The roof slab had virtually no reinforcement bars and, the layers of mud that had accumulated on top increased the dead load. As a result, the structure cracked and collapsed like a pack of cards due to the impact of the earthquake.

\section{Figure 3:}

These random rubble masonry walls collapsed during the earthquake due to improper bonding and the absence of through stones. 
to the earthquakes. On the other hand, we discovered several examples of traditional constructions that did survive these devastating earthquakes. One wonders whether any building knowledge for earthquake mitigation and earthquake-safe construction systems/features existed in traditional societies? And, if indeed it did exist, what were the reasons for its loss or degeneration?

\section{THE EARTHQUAKE SURVIVORS - REPOSITORY OF TRADITIONAL KNOWLEDGE SYSTEMS}

The vernacular structures built using local Kashmiri building techniques of Taq (timber laced masonry bearing wall) and Dhajji Dewari (Timber Frame with Masonry Infill) performed much better than many poorly built 'modern' structures. Although there were cracks in the masonry infill, in most cases these structures did not collapse, thereby preventing loss of life (Figure 4).

Also, several traditional constructions employing structurally stable stone masonry with through stones, well designed arches and retaining walls with corner bastions performed well against the earthquake. Other earthquake safe features found in several traditional constructions in earthquake affected Poonch region in Kashmir include floors/ceilings with joists resting on wooden bands (ties) running all along the walls, well designed trusses, 'tongue and groove' joinery and balconies resting on projecting wooden joists. In other constructions, extensive use of wood on the upper floor (in the form of wall paneling, balconies, staircases etc.) significantly reduced the weight, thereby enhancing the earthquake performance of the structures (Figure 5).

Such earthquake safe construction systems have also been found in Gujarat. The typical traditional dwellings of the Kutch region; the bhungas, that have withstood the test of time for centuries and have also withstood earthquakes, thanks to their circular form, which is very good in resisting lateral forces of earthquakes. Moreover, their wattle and daub constructions, especially where wood is used as reinforcement for the wall, has proved to be very effective. Its worth mentioning that bhungas are not only earthquake safe, they also demonstrate sensitive understanding of locally available resources, climatic conditions and spatial requirements of people (Figure 6). In fact, all these factors play an important role in the evolution of vernacular architecture at any given place.

In Gujarat, many structures built prior to 1950s had floor joists extending through the rubble stonewalls to support the balconies. They were more successful in stabilizing the walls than the cases where joists terminate in pockets and, therefore, performed much better against the 2001 earthquake (Langenbach 2001). In fact, in Anjar, this kind of structure was one of the rare ones still found standing amidst endless debris of collapsed houses (Figure 7). 


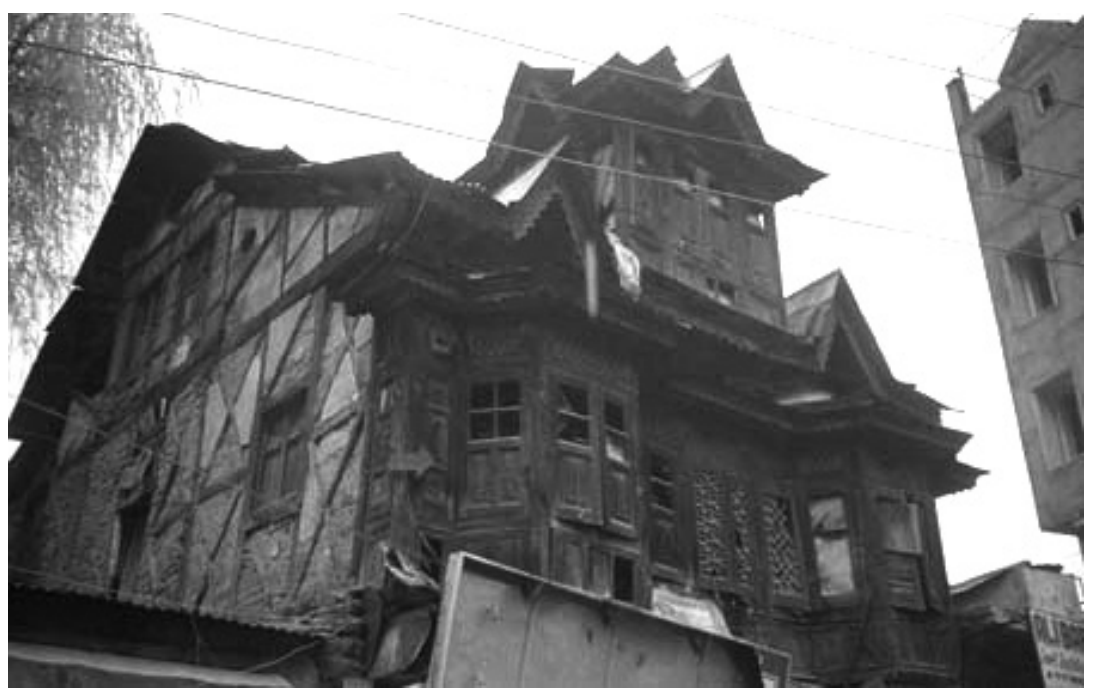

Using Traditional Knowledge

Systems

for Post-disaster

Reconstruction

Figure 4: Vernacular houses in Poonch using Kashmiri techniques of Dhajji Dewari (timber frame with masonry infill) performed much better during the earthquake than many of the poorly built 'modern' structures.

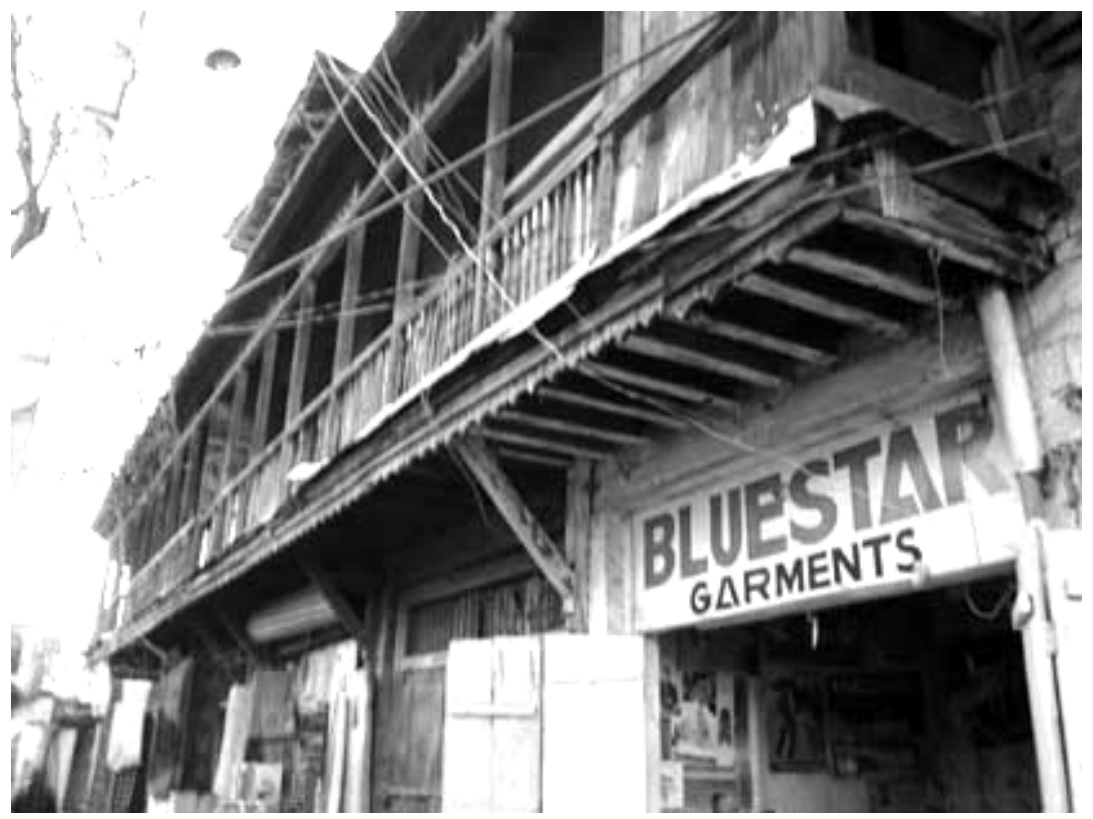

Figure 5: Another example of a traditional house with projected balconies built before 1950 that was able to withstand the 2005 earthquake. 
Some traditional constructions employing wooden frames with masonry infill also performed well against the lateral forces of the earthquake due to their capacity to dissipate the energy. Several earthquake-safe features are also to be found in many traditional constructions such as tie beams, knee bracing, tongue and groove joinery, etc. (Figure 8)

Last but not the least, useful knowledge is also embedded in traditional management systems, which act as effective coping mechanisms during disaster situations. In Gujarat, local community networks, religious and philanthrophic institutional structures played significant role in supporting post disaster recovery efforts.

Based on the above findings, we can safely conclude that traditional knowledge systems for earthquake mitigation as well as recovery did exist in earthquake prone regions in Kashmir and Gujarat, although in most cases these had largely disappeared or degenerated due to factors such as lack of maintenance, incompatible changes, poor workmanship, etc. The underlying reasons for all of these are linked to the development processes -- an issue, which though worth investigating, is outside the scope of this paper.

\section{NATURE AND SCOPE OF TRADITIONAL KNOWLEDGE FOR DISASTER MITIGATION}

In the light of above discussion, it is worth looking into the scope and nature of traditional knowledge systems. Such systems are typically developed locally under local control and use low levels of technology. Many lack bureaucratic organization. The main channels of communication of this knowledge are traditional performing arts (or 'folk media'), 'indigenous organizations', 'deliberate instruction' (child rearing, traditional schooling and apprenticeship), unstructured channels such as conversations at markets and in the field, written and memorized records and direct observation. This just goes to show that traditional knowledge encompasses the whole cultural context. Paul Sillitoe (1998) describes traditional knowledge as "by definition interdisciplinary; local people think of and manage their general environment as a whole system." Moreover it is experience-laden, practice oriented and culturally embedded, thus more holistically oriented.

Peter Schroder (1995) has aptly summarized the generally held consensus on traditional knowledge. According to him, "Traditional knowledge consists of knowledge and practical capabilities, which emerged from local conditions and natural and social surroundings, and which have often been tested over a long period of time and integrated into a larger cultural context" (translated from German by Schmuck, 2001). 

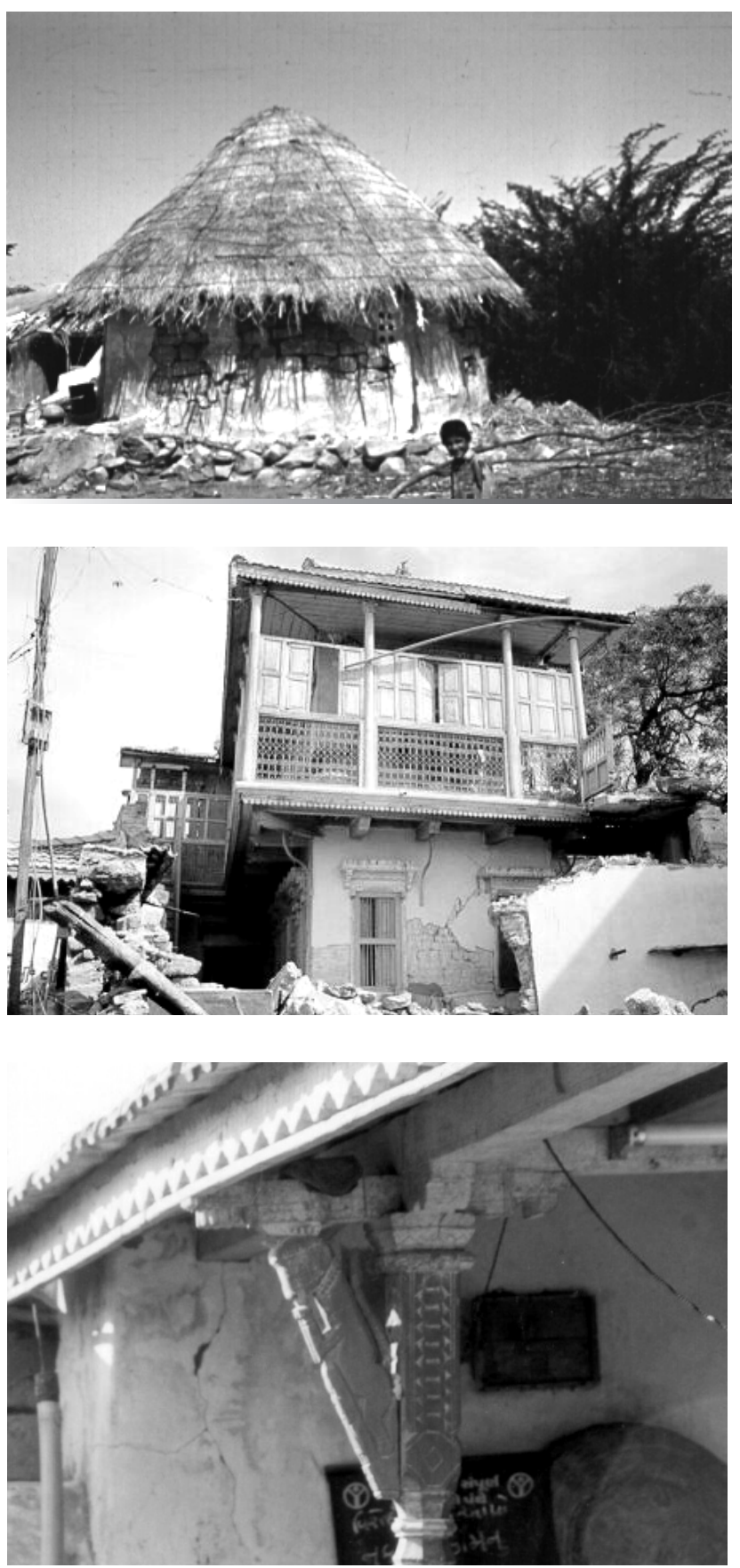

Figure 6:

Bhunga in a village near Bhuj in Gujarat. The walls are made of mud applied to an inner wooden trellis, a comparatively ductile and light system. The mud walls and the thatched roof provide reasonable cooling in the hot and arid Rann of Kutch.

\section{Figure 7:}

One of the few surviving traditional houses in Anjar which could withstand the earthquake when all newer structures collapsed like pack of cards.

\section{Figure 8:}

Several earthquake-safe features can also be found in many traditional constructions, such as knee bracing in this case.
Using Traditional Knowledge Systems for Post-disaster Reconstruction 

considered as an inherent part of traditional knowledge systems. These can be physical, social, economic and institutional. The term 'coping capacity' also carries significance in a post disaster situation. In every society, there are a variety of internal social structures that help individuals and families through difficult periods. These are known as coping mechanisms and, during disaster situations, they become collective instruments for organizing action on behalf of the disaster victims.

\section{THE CASE OF POST DISASTER RECONSTRUCTION IN KASHMIR}

Following the recent earthquake in Kashmir, it was found that in most instances, the traditional constructions, which had in fact performed better against the earthquakes, were abandoned by their owners due to a widely prevalent (though erroneous) perception that traditional buildings were 'old' and 'outdated' and, therefore, 'unsafe' and 'unlivable'. Many of these structures were also on the verge of demolition and slated for replacment by 'modern' reconstructions.

In the absence of any proper technical assistance, people started rebuilding on their own, using whatever resources were available at their disposal, including the compensation money being provided by the Government. Not many realized that the main problem did not lie with the strength of stone, but the way it was being used.

Ironically, the new constructions after the earthquake were even poorer than before because, with no technical assistance forthcoming, the victims were left with no option but to build anyhow and secure a roof over their heads as soon as possible. These new constructions were also judged to be unsustainable in terms of available skills and resources. Stone is locally available material and is a part of the local building culture. Replacing it with concrete would prove to be economically unaffordable for the far flung villages, especially those located in difficult terrain.

As a result people, started reconstructing in stone without employing earthquake safe practices (Figures $9 \& 10$ ). One of the reasons for these poor construction practices was the non-availability of trained local engineers and masons. In fact, most of the reconstruction was being undertaken by masons from Bihar, who were not conversant with sustainable local building techniques. 


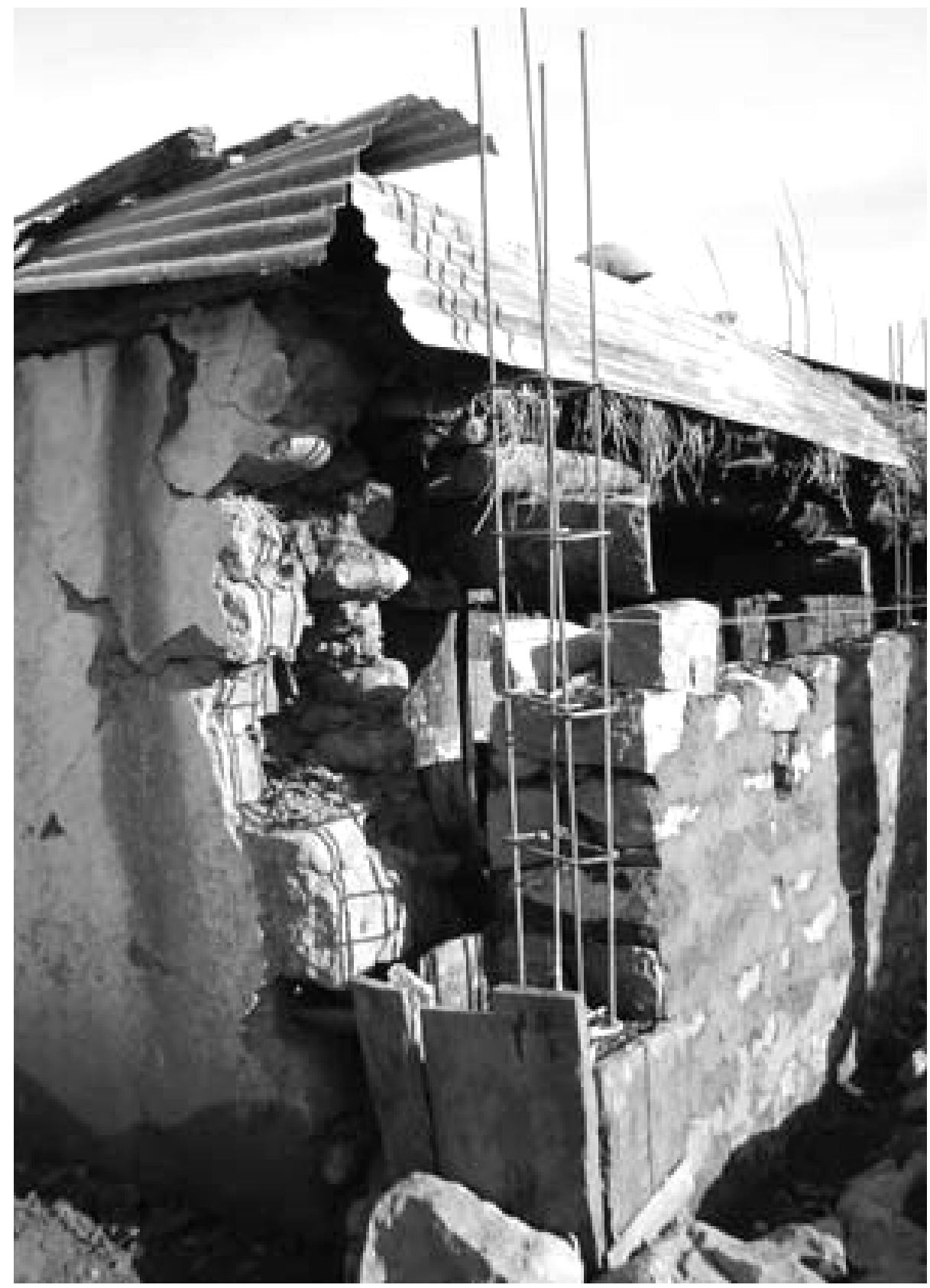

Using Traditional Knowledge Systems for Post-disaster Reconstruction

Figure 9: Reconstruction of rural houses undertaken by owners following the 2005 earthquake in Kashmir indicate ignorance of techniques for earthquake resistance. 
Jigyasu, R.

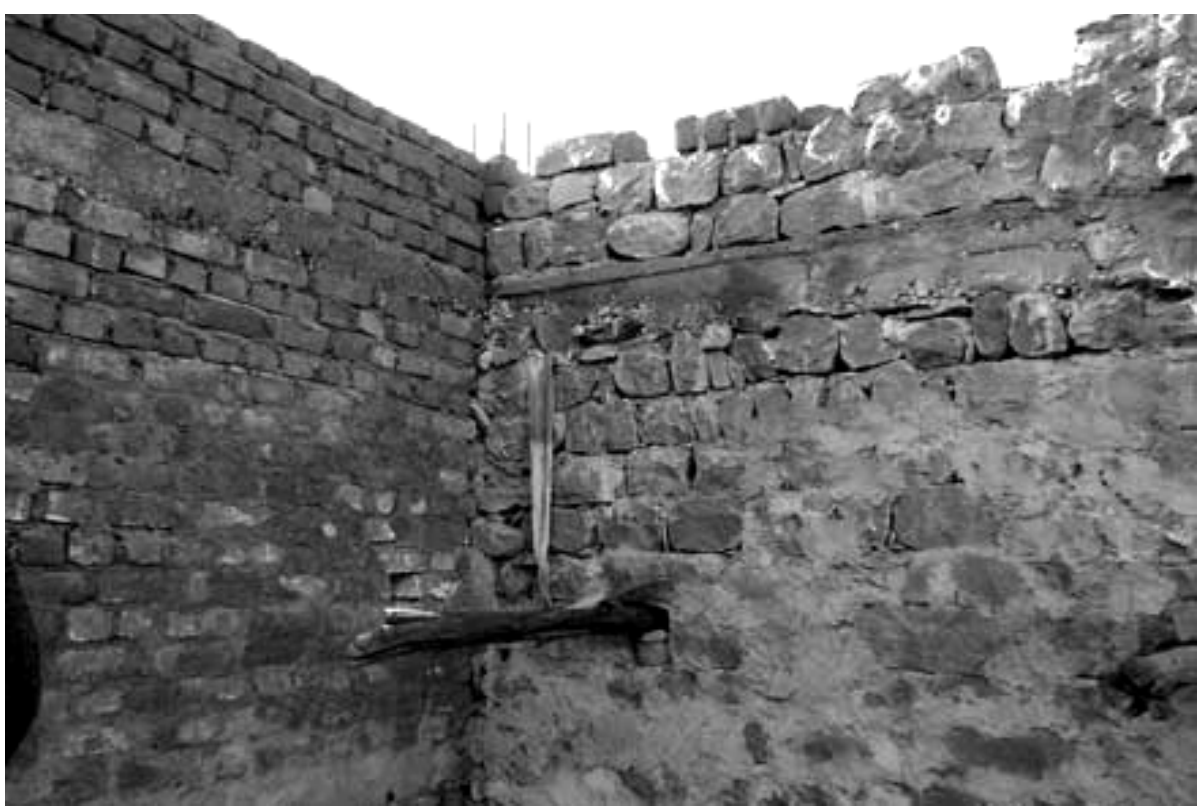

Figure 10: Reconstruction of rural houses in Kashmir. The use of composite materials and discontinuous concrete bands indicate a total disregard for basic techniques for earthquake resistance.

\section{RECONSTRUCTION IN GUJARAT - FROM 'NATURAL' TO CULTURAL 'DISASTER'}

In the case of Gujarat, the villagers were eventually left with two options either to choose financial compensation offered by the government, or to let the donor agencies undertake full-fledged adoption and reconstruction. Finally, majority of the people decided to go for financial compensation and expressed their desire to undertake construction on their own (Jigyasu 2001).

As a consequence of all this, many NGOs came forward to help local communities in deciding the design layout and structural system of new construction. Most of them promoted self-help construction by providing the beneficiaries with construction materials like wood, bamboo spread sheets or concrete blocks, reinforcement bars, etc. according to the structural design advocated by the concerned NGO. The local communities were involved in providing labour for tasks such as curing, block-laying, etc. Junior engineers were hired from other areas to coordinate the construction activity. As part of public-private partnership policy, the government made available the building materials in a subsidised way (ibid). 


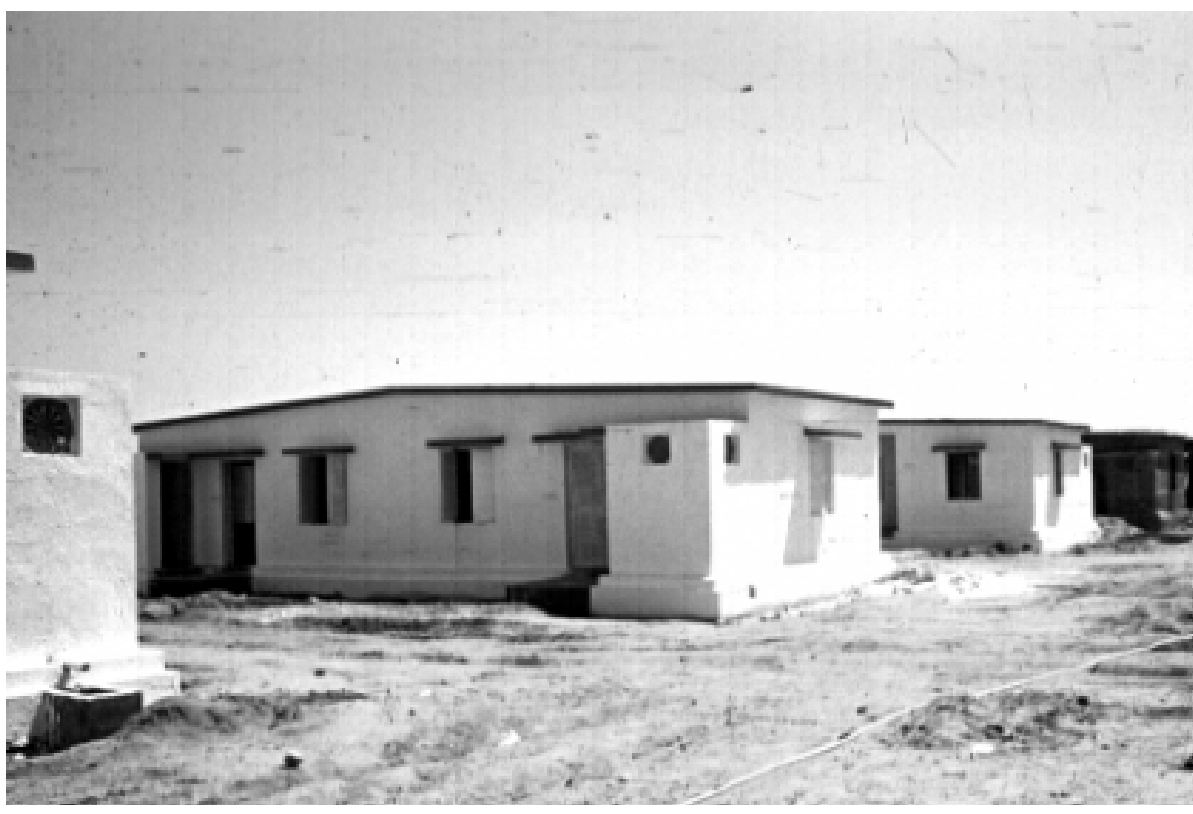

Using Traditional Knowledge

Systems

for Post-disaster

Reconstruction

Figure 11: Contractor driven reconstructed village following grid iron pattern and box shaped houses show total disregard for the traditional way of life.

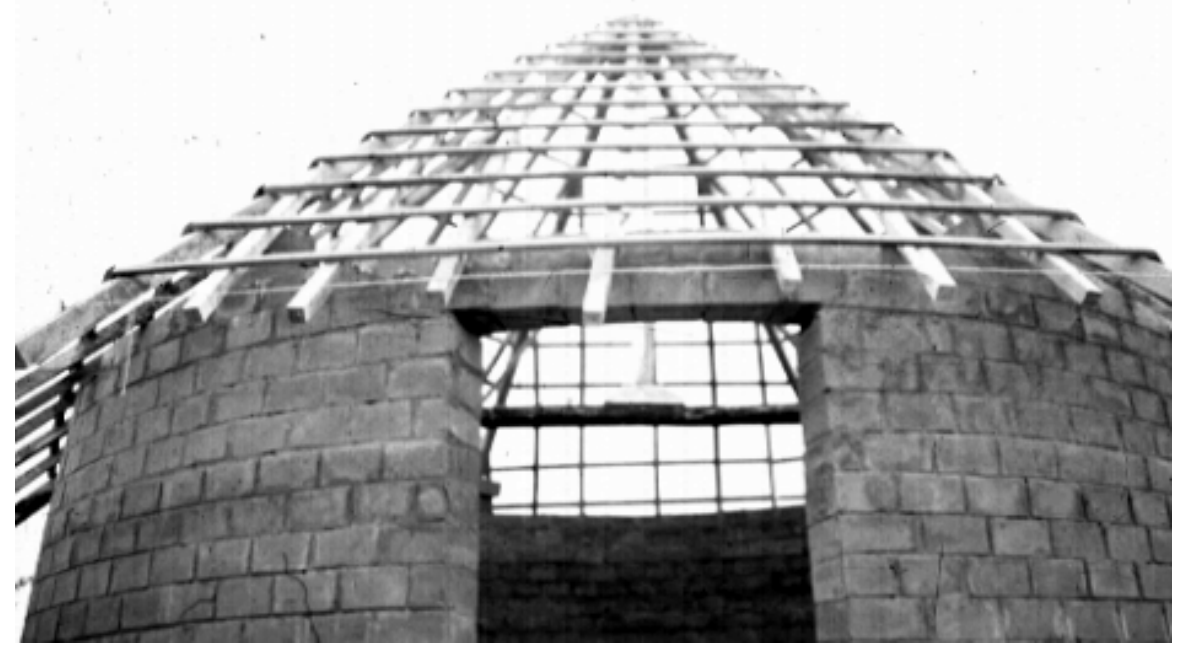

Figure 12: Modern Bhungas, constructed by an NGO after the earthquake, retain traditional circular forms but have replaced traditional materials by low-cost compressed soil blocks. 
Jigyasu, R.

\section{'Adopted' villages - culturally compatible?}

While the owner-driven approach was on the main agenda of the Government, it also paved the way for a 'full-fledged adoption of villages' through contractordriven reconstruction programmes. In these villages, the construction labour was essentially hired from outside, and local villagers had no say and no role in the reconstruction process.

In many of these villages, the 'city-like' layout and the government criteria of house-size, overlooking traditional spatial planning and design systems, brought out the issue of 'cultural incompatibility'(Figure11).

In some villages, traditional circular structures (bhungas) were reconstructed. However, these merely copied the form while changing local materials and technology, bringing forward issues related to their authenticity and sustainability (Figure 12).

\section{'Alternate' technology - how sustainable?}

Besides the 'modern' techniques, some NGOs also explored various options for 'alternative' design and technology for earthquake resistant construction. A consortium of NGOs promoted construction of structures using precast 'compressed soil blocks' with or without interlocking dry stacked masonry system, ring reinforcement and wooden rafters. It has also set up a laboratory to experiment and test 'new' technologies.

However, such alternate methods also required strict quality control. During construction phase, the concerned NGO took care of this. But, once these organizations withdrew from the scene, and since these technologies were not based on traditional knowledge and the constructions required proper curing (a difficult proposition in a drought prone area), there were serious questions regarding 'internalizing' them within the local community. Whether such technologies would be able to take roots within the local building culture of the area was highly doubtful.

\section{Unsafe practises in self-help constructions}

No matter how NGOs and, to some extent the Government, were facilitating reconstruction, earthquake-safe features were not being employed in many self-help constructions, thanks to the general ignorance regarding them. The situation is strikingly similar to that in Kashmir.

The government and some NGOs advocated the concept of semipermanent shelters as an intermediate solution, mainly to protect the victims from monsoons that would arrive before the people could move into their permanent houses. 


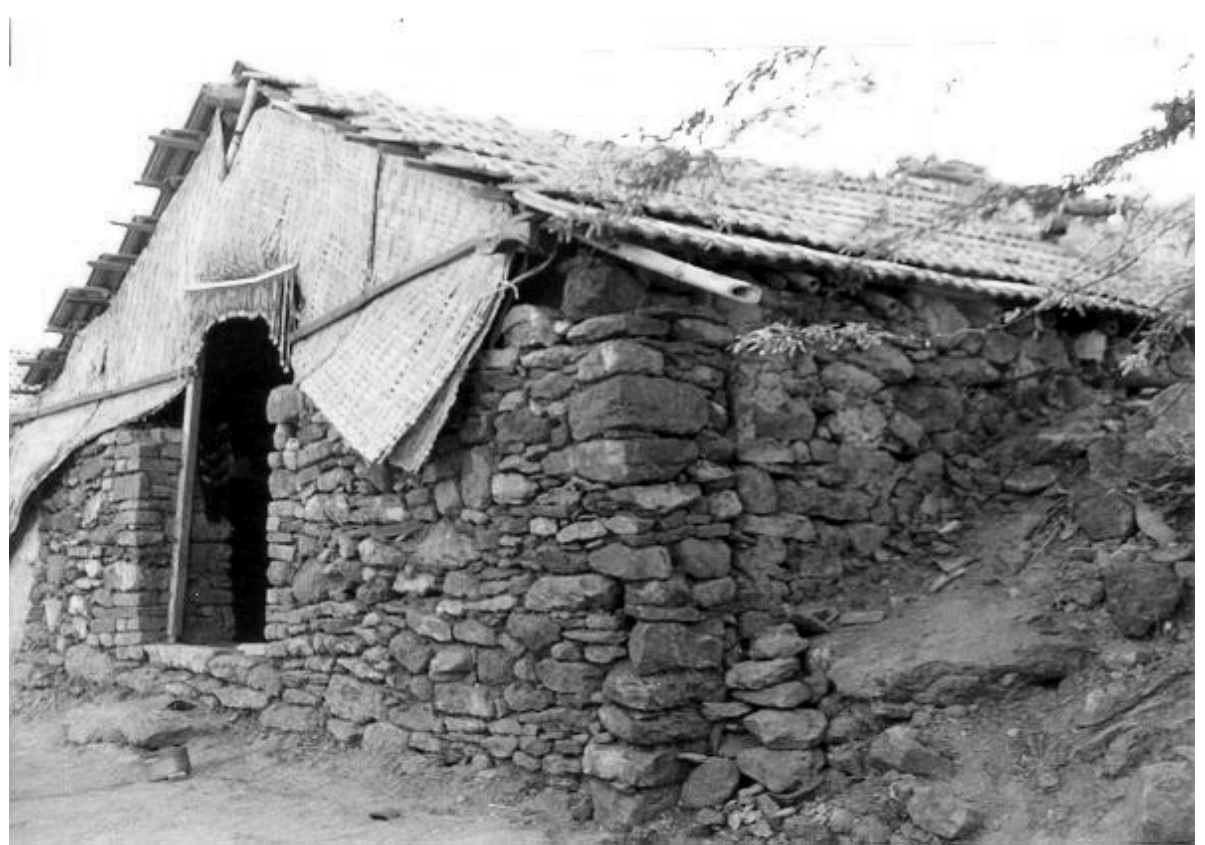

Figure 13: Conversion of temporary shelters to permanent houses

However, this did not materialise in time. As a result, by the time the semipermanent shelters could be erected, people had already initiated permanent constructions and reverted to prevalent unsafe building practices. Over time, many semi-permanent constructions were also made permanent by raising walls in stone, again without any earthquake safe features (Figure 13).

\section{Repairs, Strengthening and Retrofitting - continuing misperceptions}

Wrong repairs were also seen everywhere. People had filled up 'through cracks' with cement grout and then moved back to their houses. Some difficulties were experienced in implementing the strengthening and retrofitting programme because of prevailing misperceptions and bias against traditional buildings, which discouraged people from undertaking these measures. Moreover, the emphasis of decision-makers seemed to be on the number of new houses being reconstructed rather than safe practices.

Wrong perceptions were also evident in the way traditional structures were being pulled down, even where they were still standing, to make way for 'modern' structures, especially in historic towns such as Anjar, Bhuj and Morbi. Ironically, in most cases, thanks to poor workmanship and undue costs the new structures were not any better.
Using Traditional Knowledge Systems for Post-disaster Reconstruction 

LOCAL KNOWLEDGE

Therefore, the key issue here is the loss or degeneration of traditional building systems over last few decades. It is this primary factor which made the buildings vulnerable to disasters in the first place, and then reinforced, and in some cases even increased their intrinsic vulnerability during post-disaster reconstruction. The underlying reasons for this loss or degeneration, therefore, need to be explored seriously.

First of all, economy influenced owner's choice of materials and lowering of specifications, both before and after the disaster. For example, wood was one of the primary building materials for housing in several earthquake prone regions. Further, its combination with stone masonry helped in better seismic performance. However, wood slowly became unaffordable and, therefore, people started making alterations to their buildings, which in many cases made them more vulnerable to earthquakes. For example, in the Kutch region of Gujarat as well as in the Poonch region of Jammu and Kashmir, walls were extended up to over 15 feet in unbraced height, simply to support the ridge of the roof while avoiding use of wood necessary to build a roof truss. Also in many instances, sophisticated joinery using tongue and groove joints got replaced with simple nailing of wooden members, even though this could easily give way in the event of an earthquake.

Secondly, overriding perceptions favored the use of new materials like cement while overlooking the traditional use of mud, which was perceived as 'weak' and 'outdated'. Needless to say, some of the essential construction specifications attached with the new materials and technology were not feasible in many earthquake prone regions owing to the local unavailability of resources. For example, appropriate curing of concrete is virtually impossible in the drought prone regions of Kutch. Moreover, poor economy also forced people to make ill-advised compromises in their constructions.

Thirdly, with the introduction of new materials, the original strength of the traditional materials could not be used effectively for withstanding lateral forces of earthquakes. New materials such as brick and concrete, were combined randomly with traditional materials such as stone and wood even in post earthquake reconstructions, thereby adversely affecting their structural integrity and seismic performance.

Last but not the least, with changed materials and technology, the traditional craftsmen found themselves incapable of using their skills. Local masons, who were skilled to shape and lay stones, were not trained to handle brick and concrete constructions. While on the one hand, they found themselves 
incapable of using new materials, their own knowledge of stone masonry degenerated to a considerable extent, primarily because of lack of demand for traditional constructions over last few decades. This situation forced them to move to other occupations and, therefore, successive generations could not imbibe the skills from their masters. Even those who could afford modern RCC constructions could not afford the level of workmanship required for traditional constructions due to unavailability of skilled workforce. Extensive role of outside craftsmen, who are unfamiliar with traditional construction practices, before and after the earthquake, have made matters more complicated.

Also, most of the post earthquake interventions from outside conceive earthquake resistant technology as a 'packaged product' for fast duplication and transfer. Ironically traditional knowledge systems are also in danger of falling in the same trap if they are looked at in a static manner. This issue will be taken up in the next section.

It won't be wrong to conclude that the traditional knowledge has been lost or has degenerated mainly because its process of evolution has been disrupted, thereby putting a stop to the 'creative' search for solutions through continuous trial and error. In fact, this evolutionary process is what defines the true essence of traditional knowledge.

\section{CRITICAL CHALLENGES FOR MAINSTREAMING TRADITIONAL KNOWLEDGE}

\section{'Heritage' - elitist or inclusive?}

A predominant perception among professionals as well as local communities is that cultural heritage is limited only to a select group of monuments or objects and, in that sense, is elitist. Therefore, concerns for cultural heritage in disaster management are seen as secondary, with an understandable logic that concerns for saving lives and livelihoods should take precedence over preservation of cultural heritage.

However, the scope of cultural heritage has extended way beyond select monuments, group of buildings or objects to include vernacular houses, historic urban areas, cultural landscapes and even intangible dimensions of living heritage such as skills and cultural practices.

This expanded scope of heritage needs to be integrated within various development and disaster risk management sectors through redefining and repackaging heritage concerns through regenerating traditional livelihoods, ecological planning, sustainable development, etc. 
A large part of the writing on local knowledge attempts to 'package' and 'market' traditional knowledge as something complete in itself, especially by marking an artificial boundary between it and formalized, scientific knowledge (Schmuck 2001).

However, Richards (1994) rightly emphasizes experimentation as an important aspect of traditional knowledge, and thus makes a claim that traditional knowledge is scientific. According to him, "Traditional knowledge is knowledge that is in conformity with general scientific principles, but which, because it embodies place-specific experience, allows better assessment of risk factors in production decision. This kind of knowledge arises where local people undertake their own experimentation, or where they are able to draw inferences from experience and natural experiments."

The same emphasis is given by Flavier et al. (1995), who state that traditional information systems are dynamic, and are continually influenced by internal creativity and experimentation as well as contact with external systems. This continuous process of experimentation, innovation and adaptation enables traditional knowledge to blend with science and technology as well.

Therefore, rather than categorizing traditional and scientific knowledge into mutually exclusive domains, attempts should be made to recover 'scientific' aspects of traditional knowledge and 'traditional' aspects of 'scientific knowledge'. While the former will enable traditional knowledge systems to be easily understood by professionals, the latter would demand that larger scientific concepts get translated into modes of communication that are locally understood. This process of rediscovering, recovering, encoding and decoding is an organized scientific activity in itself.

\section{Replacing, Restoring or Evolving?}

Critical choices need to be made regarding the basic philosophy governing post disaster interventions and the role of traditional knowledge in developing these. Should we restore the traditional knowledge systems by recovering and reusing them in a manner they would have existed in their pristine glory? Or, should we attempt to restore their essence by bringing back the creative process of evolution responding to changing needs, constraints as well as aspirations but, at the same time, maintaining the local sense of identity and building on the accumulated experience of the past? The latter seems to be an obvious choice if we wish cultural heritage to play a proactive role in disaster mitigation and recovery.

If we want to protect cultural heritage in the post disaster situation, we must prevent its replacement by seemingly 'modern' but culturally, climatically and 
economically unsustainable reconstructions. This requires us to address post disaster rehabilitation in two ways. Firstly, by developing workable alternatives for repair and retrofitting of traditional and historic structures, which may have got damaged but did not collapse. This would be more appropriate rather than 'standard engineering recipes and design packages', especially in cases, where this is a feasible option. Secondly, engagement in a process of a culturally sensitive reconstruction that builds on the accumulated knowledge of the past, not only fosters local identity but, at the same time, addresses new needs and aspirations including that of seismic safety. This may also require lowering the earthquake safe thresholds by establishing optimum acceptable standards for managing risks in response to local constraints and opportunities.

Last but not the least, this would demand real community engagement through empowerment and not merely the rhetoric of participation.
Using Traditional Knowledge Systems for Post-disaster Reconstruction

\section{REFERENCES}

Flavier, J.M. et al. (1995) "The regional program for the promotion of indigenous knowledge in Asia", pp. 479-487 in Warren, D.M., L.J. Slikkerveer and D. Brokensha (eds) The cultural dimension of development: Indigenous knowledge systems (Intermediate Technology Publications, London)

Jigyasu, R. (2002), 'Reducing Disaster Vulnerability through Local Knowledge and Capacity', Dr. of Engineering thesis, Department of Urban Design and Planning, Norwegian University of Science and Technology, Trondheim.

Paul Sillitoe et. al (1998), 'Participating in Development. Approaches to Indigenous Knowledge', ASA Monographs 39 (Routledge, London)

Richards, P. (1985), Indigenous Agricultural Revolution; Ecology and Food Production in West Africa (Hutchinson, London).

Recommendations of "UNESCO-ICCROM-Agency for Cultural Affairs of Japan: Thematic Meeting on Cultural Heritage Risk Management", World Conference on Disaster Reduction (WCDR), 18-22 January 2005, Kobe, Japan

Schmuck-Widmann, H. (2001) Facing the Jamuna River - Indigenous and engineering knowledge in Bangladesh, Bangladesh Resource Centre for Indigenous Knowledge.

"The Hyogo framework for action (2005-2015): 'Building the Resilience of Nations and Communities to Disasters, World Conference on Disaster Reduction (WCDR), 18-22 January 2005, Kobe, Japan 